PF 2019 (LXXIV): 427-442

\author{
KAZIMIERZ SIKORA \\ Katedra Historii Języka i Dialektologii \\ Wydział Polonistyki \\ Uniwersytet Jagielloński \\ ul. Gołębia 16, \\ 31-007 Kraków \\ tel. +48126631403 \\ e-mail: k.sikora@uj.edu.pl
}

\title{
KRAKÓW SPOD CIEMNEJ GWIAZDY W SYMBOLICZNEJ PRZESTRZENI MIASTA
}

SŁOWA KLUCZOWE: językowy obraz świata, folklor miejski, Kraków.

KEYWORDS: linguistic worldview, urban folklore, Kraków.

\section{KRAKÓW OF THE DEEPEST DYE IN THE SYMBOLIC SPHERE OF THE CITY}

\begin{abstract}
The article discusses the functioning of traditional urban folklore in the contemporary symbolic sphere of the city. For this purpose, it analyses changes of meaning (melioration) and systemic connotations (idealisation) of a selected group of lexemes naming people from the underworld. Its conclusion is that the process of creating a positive image of these people should be associated with mythologization of the past and figures of pop culture and folk culture. The language of the suburbs of Kraków (nowadays eagerly used in regional advertising), just like the dialect of the Polish highlanders, is a good example of such cultural promotion of the "goodfellas".
\end{abstract}

Inspiracją do zajęcia się problematyką obecności dawnych „bohaterów przedmieść" i przedstawicieli półświatka w miejskim folklorze Krakowa była głośna pod Wawelem wystawa „Andrusy, kindry, agary... Z przedmieść Krakowa” (15 XI 2013 - 9 III 2014), przygotowana przez Dom Zwierzyniecki - oddział Muzeum Historycznego Miasta Krakowa, mieszczący się u stóp wzgórza bł. Bronisławy 
(Sikornika) i kopca Kościuszki. Muzeum zaprosiło zwiedzających na barwną i dowcipną opowieść o miejskim folklorze Krakowa z początku XX wieku, która miała w zamierzeniu twórców: „przybliżać zwiedzającym bogactwo historii i kultury przedmieść Krakowa"2.

Wystawa, przygotowana przez znawców zagadnienia, miała upamiętniać „podwórkowy” Kraków sprzed lat, w istocie rzeczy jednak nie tak dawny, przecież ten z czasów młodości Gustawa Holoubka, Danuty Rinn, Jerzego Harasymowicza, Mieczysława Święcickiego, Zygmunta Koniecznego, Jana Kantego Pawluśkiewicza, Wiktora Sadeckiego, Jerzego Treli, Leszka Piskorza - Kindra z Grzegórzek ${ }^{3}$, a także przywrócić pamięć o Zaczarowanej Dorożce Jana Kaczary zmarłego w 1980 r. (dorożka z takim złotym napisem jeździła po Krakowie aż do 1985 r., kiedy uległa zniszczeniu w wypadku), dokonaniach Piotra Skrzyneckiego i Piwnicy pod Baranami, wreszcie podnieść żywą obecność w intelektualnym pejzażu Miasta godnych kontynuatorów tej tradycji: Andrzeja Sikorowskiego, Anny Dymnej, Anny Szałapak, Jacka Wójcickiego, Grzegorza Turnaua... Wprowadzam tu moje reminiscencje $\mathrm{z}$ tego spotkania, by podkreślić, że Kraków jest kulturową przestrzenią wyjątkowo sprzyjającą mitologizacji przeszłości ${ }^{4}$.

Miejsce na wystawę też wybrano nieprzypadkowe, bo to szczególne miejsce w kulturowym pejzażu miasta. Na Zwierzyńcu odbywa się w każdy poniedziałek wielkanocny słynny odpust i kiermasz Emaus, stąd wyrusza w oktawę Bożego Ciała na Rynek Główny pochód Lajkonika, tu wreszcie znajdował się zamknięty w 1991 r. (właściciel nie dostał koncesji na wyszynk alkoholu...) legendarny Bar na Stawach, upamiętniony przez Jerzego Harasymowicza. Trudno sobie (i, jak

1 Kopiec Kościuszki, nadal pozostający „pielgrzymkową górą Polaków” góruje nad miastem i nad zabudowaniami krakowskiej dzielnicy Zwierzyniec. W pogodne, wolne od smogu dni z kopca Kościuszki oczom zwiedzających ukazuje się najpiękniejsza panorama Krakowa. Dom Zwierzyniecki znajduje się blisko Błoń, przy ulicy Królowej Jadwigi 41.

2 Materiały promocyjne, $\mathrm{w}$ tym interesujący, kilkuminutowy filmowy zwiastun wystawy, można nadal obejrzeć w Internecie (portal youtube). Dla porządku dodajmy, że o półświatku Krakowa z czasów przedindustrialnych i jeszcze odleglejszych niewiele (poza źródłami stricte historycznymi) wiadomo; onomastyczną pamiątką po nich są ulice: Facimiech i Dajwór, niedwuznacznie wskazujące na niecny proceder rzezimieszków. Ogólną orientację w tym zakresie dają prace: Jakubowski 2016 oraz Kracik, Rożek 2012, wskazane w bibliografii.

3 W tej galerii sławnych podówczas (i dzisiaj), związanych blisko ze Zwierzyńcem i Krakowem aktorów, piosenkarzy, poetów, kompozytorów, artystów kabaretowych jest jeszcze kilka dziesiątków nazwisk do wymienienia. Nie czyni się tego z braku miejsca (choć dopominałyby się o to krakowskie maniery). Leszek Piskorz, aktor Starego Teatru (urodzony na krakowskich Grzegórzkach) jest autorem wspomnień (autobiografii) pod tytułem: Ja, Kinder z Grzegórzek (2008).

4 Nazwiska publicystów i twórców - piewców uroków dawnego i podmiejskiego Krakowa wymieniam przy dalszej sposobności. 


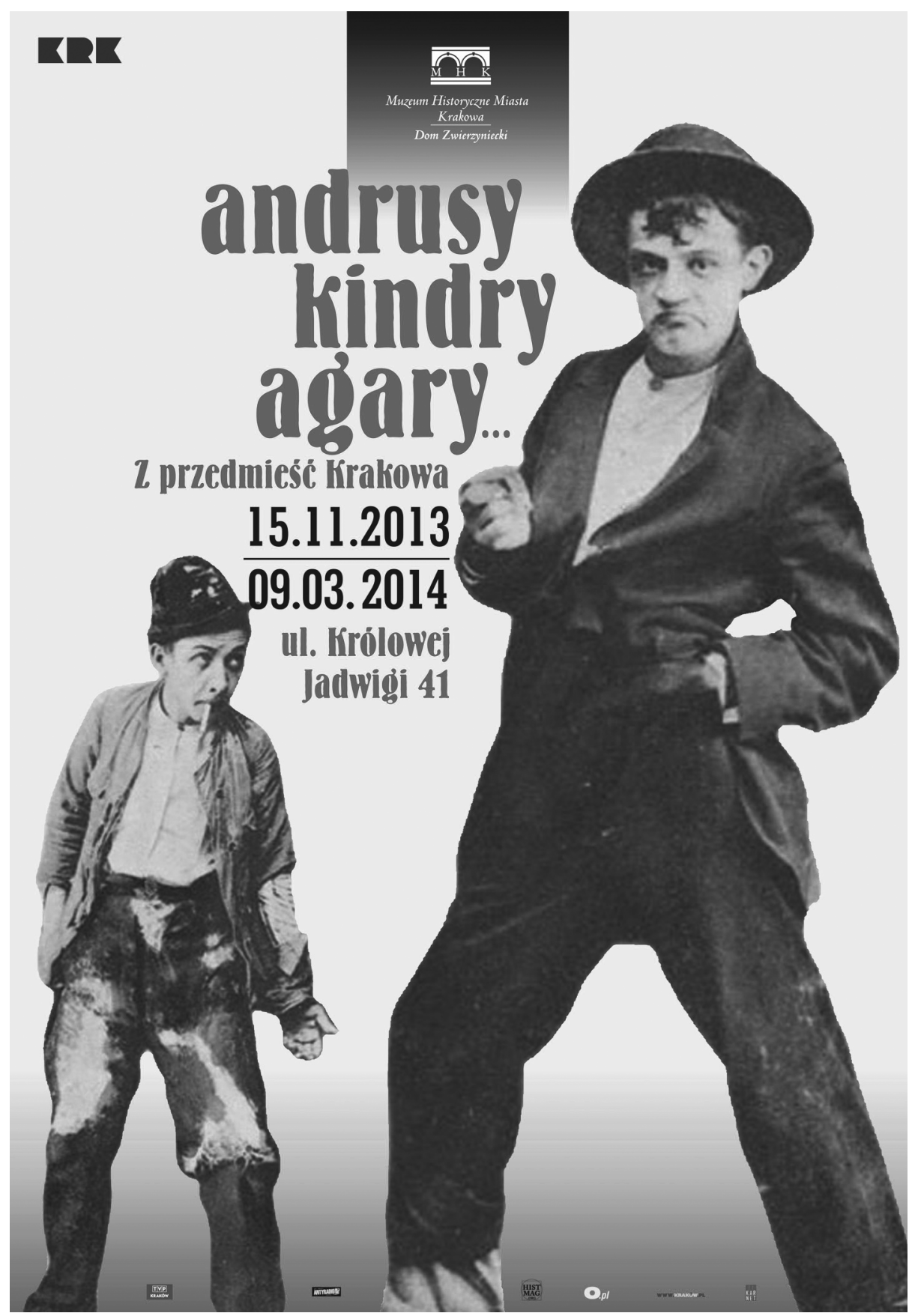

Plakat wystawy Andrusy... (ze zbiorów Muzeum Historycznego Miasta Krakowa Oddział Dom Zwierzyniecki) 
mniemam, Zacnemu Czytelnikowi) odmówić tej przyjemności i nie zacytować fragmentu jego poematu pod tym samym tytułem:

Nieraz pytają za kim jestem

W tym kraju częsta to sprawa

Mówię najbardziej popieram szyld

Z napisem „Bar Na Stawach”

Tam Maks Wózek przychodzi i Rufino

Goście z tysiąca i jednej zwierzynieckiej nocy

Tam zielone pachnie nocy piwo

Tam się schodzą placowe drogi

Burżujek tu bywa i Kazek Dycha

Sam Główeczka Tolo Malarz Poldek Śpiewak

Tu baronów swych przedstawia ulica

$\mathrm{Tu}$ jest wolnokieszonkowa strefa

Czasem zabraknie kogoś - salute!

$\mathrm{Z}$ piwa zielony nagrobek mu kładą

Nad Norbertanki uleciał Edek

Gdzieś na wieży siedzi denato

I zadzwoniły kufle po nim

$\mathrm{Na}$ tę parkanów przedmieścia nostalgię

Poniosły go kawki na skrzydłach

Bo kawki mają garnitury czarne

I leci krótki - trzy wina bier

I król brodaty biber kier

Jedną swą rąszką trzymie korone

Drugą wskazuje karty znaczone

Kończy się szefku pasaż

Kieszonkowa strefa nasza

I koń który w łąki srokaty

Elektryczne mija światy

(Harasymowicz 1973)

Fascynacji tym miejscem, przedmieściem i twórczością samego Harasymowicza dowodzi też tekst piosenki Bar na Stawach Wolnej Grupy Bukowina, autorstwa Wojciecha Bellona. Jest to już zdecydowanie pożegnanie z mityczną przestrzenią krakowskiego przedmieścia, na które składają się prócz Półwsia Zwierzynieckiego także inne dawniejsze wioski - przedmieścia: Ludwinów, Czarna Wieś, Grzegórzki, Krowodrza, Dębniki. 


\section{Bar na Stawach}

(słowa i muzyka Wojciech Bellon)

Jeszcze się z nocy kołysze miasto

Ósma piętnaście Na Stawach Bar

Bramy otwiera - wchodzimy tedy

Ja i Hnatowicz Jan

Co tu zostało z wierszy Mistrza

Klasa robotnicza, fasolka $\mathrm{z}$ bufetu

A smak poranny piwa

Łapczywie poznają poematy w beretach

Wszedł dzielnicowy krokiem szeryfa

Tępo spod dacha popatrzył

Nie mieści mu się w głowie służbowej

Że można wypić na czczo

Co tu zostało z wierszy Mistrza

Kiedy wyjść trzeba na papierosa

A bufetowa grozi gliną

Gdy ktoś coś powie głośniej

Pod ścianą zaraz przy wejściu

Paląc sporty z rękawa

Siedli goście wprost $\mathrm{z}$ wierszy Mistrza

Bubu, Makino - wypisz wymaluj

Słuchaliśmy ich z Hnatowiczem

Jak żywy poemat Stawów

Poezją był brzęk ich kufli

Kosmiczny wymiar miały słowa

Lecz chłopakom od sąsiedniego stolika

Chyba z zawodówki pobliskiej

Nagle się dziwnie zachciało

Żeby te zgredy wyszli

Co tu zostało z wierszy Mistrza

Chłodem powiało od drzwi nie domkniętych

I wyszliśmy z Hnatowiczem

Gdzie indziej szukać poezji (Bellona)

Tradycja, pamięć tego miejsca „gdzie bije serce Krakowa”, utrwalanego zarówno w poezji, jak i w popularnych tekstach kultury (np. wodewile Konstantego Krumłowskiego, Stefana Turskiego, Władysława Krzemińskiego) oraz krakow- 
skiej twórczości literackiej w jakiejś części przynajmniej pozostaje żywa. Jeszcze w 2015 roku, 20 czerwca, odbył się tu VI Wodewilowy Bal na Stawach z udziałem wielu krakowskich artystów i władz miasta. Kontynuuje się w ten sposób tradycję imprez rozrywkowych urządzanych na Zwierzyńcu (od lat 80. - pod nazwą „Bal na Placu”) z okazji Dni Krakowa na placu Na Stawach z inicjatywy Aleksandra „Makina” Łodzi Kobylińskiego (lidera najpierw zespołu Szmelcpaka, a potem Andrusów). Obok muzyki wodewilowej, estradowej i tańców pojawiał się odgrywający hejnał trębacz z Wieży Mariackiej, temperaturę zabawy podnosiły igrce Lajkonika. Było oczywiście beczkowe piwo, pieczona kiełbasa i krachla (oranżada) dla dzieci, kobiet i abstynentów ${ }^{5}$. W latach 90. ubiegłego wieku w tej przypominającej festyn zabawie brały udział tysiące mieszkańców Zwierzyńca i Krakowa. Trzeba z niejakim smutkiem stwierdzić, że są to ostatnie żywe przejawy obecności tradycyjnego folkloru przedmieść w socjosemantycznej przestrzeni Krakowa. Dlatego też poświęcono im nieco więcej uwagi. Ostatnim łącznikiem z tamtym pokładem lokalnej kultury i tradycji pozostaje niezmordowany „Makino” Kobyliński, legendarny muzyk estradowy, „baron ulicy" kultywujący tradycje muzyki podwórkowej Krakowa ${ }^{6}$. Odkrywczy i pełen ciepła i humoru portret takich jak Makino „zwierzynieckich zuchów” z krakowskiej „paki” (zapewne z niej i z niebywałej popularności Królowej przedmieścia Konstantego Krumłowskiego wywodzi się warszawska „ferajna” i zainteresowanie miejskim folklorem stolicy ${ }^{7}$ ) dała ostatnio Katarzyna Siwiec w dwóch swoich książkach o Krakowie i kulturze zwierzynieckiego przedmieścia (Siwiec 2010, 2014). Charakterystyczne postaci szemranych bohaterów przedmieść (andrusów, kindrów, agarów, antków, brzan, baciarów itp.) włączył do swoich haseł nowo wydany słownik regionalizmów krakowskich ${ }^{8}$, z przekonaniem traktując te nazwy jako swoiste symbole kulturowe krakowskiego przedmieścia.

Warto na otwarcie kolejnego wątku rozważań podkreślić, że Półwsie Zwierzynieckie, które rozciąga się między krakowskimi Błoniami, Wisłą, Rudawą a al. Krasińskiego, dzisiaj będące częścią dzielnicy Zwierzyniec, stało się swoistą wizytówką miejskiego folkloru Krakowa. Czy zasłużenie, trudno jednoznacznie

5 Por relację w prasie krakowskiej (Mrowiec, Stachnik).

6 Aleksander „Makino” Łodzia Kobyliński nazywany jest też „królem andrusów”, ponieważ swoim ubiorem i swobodnym, „burszowskim” stylem życia nawiązuje do czasów przedwojennego i powojennego Krakowa. To jego barwną postać utrwalił Harasymowicz w poemacie „Bar na Stawach” i w innych swoich „krakowskich” utworach.

7 Odradzanie się zainteresowania półświatkiem dawnej Warszawy, miejskim folklorem i jego bohaterami potwierdza np. ciesząca się popularnością (kilka wydań) książka Stanisława Milewskiego, Szemrane towarzystwo niegdysiejszej Warszawy (Milewski 2009).

8 Powiedziane po krakowsku. Słownik regionalizmów krakowskich (PpK). Autor artykułu, zarazem współautor PpK, odpowiadał za przygotowanie tych haseł. 
rozstrzygnąć, skoro do takiej roli mogłyby aspirować np. Czarna Wieś, Krowodrza, Łobzów, Grzegórzki, Ludwinów9. Idźmy dalej tym tropem, by zbliżyć się do fenomenu rosnącej popularności regionalnych wartości i promocji kulturowej odrębności wielkich polskich miast. Dodajmy, że wartości wydawałoby się niejednokrotnie anachronicznych (dlatego przetwarzanych ${ }^{10}$ ) i mało przydatnych z perspektywy współczesności (np. gwara miejska, niewyszukane potrawy ubogiej kuchni ${ }^{11}$, trywialna obrzędowość świecka, na poły ludowa muzyka itp.), dla których być może najwłaściwszym kontekstem interpretacyjnym byłoby poszukiwanie „naszości” i tożsamości w globalizującym się świecie. Można na tę tendencję spojrzeć także z innej strony.

Miasto potrzebuje dla nowocześnie rozumianego marketingu nie tylko rzutkich menedżerów, ale i barwnych postaci, własnej (dziś chętnie dokumentowanej naukowo ${ }^{12}$ ) gwary, tradycji i muzyki (jak jest w Poznaniu, w Łodzi, Warszawie; było i jest po części w przedwojennym Lwowie), bohaterów, bardów ulicznego folkloru i miejskiej legendy (np. w Warszawie Stanisława Grzesiuka, Staśka Wielanka czy Felka Zdankiewicza ${ }^{13}$ ); ich popularności nie zagraża nawet to,

9 To dawne wioski, wchłonięte przez miejską zabudowę rozwijającego się coraz bardziej, „urzędniczo-profesorsko-inteligenckiego i kupiecko-rzemieślniczego" (Chrobaczyński 2004: 67) C.K. Wielkiego Krakowa (w wypadku wymienionych wiosek-przedmieść stało się to ostatecznie po reformie administracyjnej z 1910 r.). Szerzej na ten temat we Wstępie do PpK i w cytowanym artykule Jacka Chrobaczyńskiego. Przystępnie o powstawaniu tego szczególnego organizmu miejskiego na stronie: https://pl.wikipedia.org/wiki/Historia_podzia\%C5\%82\%C3\%B3w_administracyjnych_Krakowa [dostęp 6.01.2019]. O dziedzictwie habsburskim i „wiedeńskim szyku” Krakowa Matejki, Kossaków, Wyspiańskiego, Rydla, Przybyszewskiego, Boya-Żeleńskiego i Zielonego Balonika w książce Kraków cesarsko-królewski (Skowroński 2003).

10 Por. muzyczną działalność Projektu Warszawiak (od 2011 r.), wykonującego w nowych aranżacjach stary warszawski folklor muzyczny (np. piosenkę Grzesiuka Nie masz cwaniaka nad warszawiaka: https://www.youtube.com/watch?v=Ty-3SDp7cb8 [dostęp 1.12.2018]). Dla zyskania pożądanego dystansu por. też książkę Bronisława Wieczorkiewicza, Warszawskie ballady podwórzowe (1971).

11 Por. postne, wielkopolskie pyry $z$ gzikiem (ziemniaki w mundurkach $\mathrm{z}$ twarogiem) albo góralskie moskole (placki pieczone na blasze pieca) lub podkarpackie proziaki (placki na sodzie oczyszczonej pieczone na blasze) - cieszące się wielką popularnością specjały kuchni regionalnej.

12 Por. np. Gruchmanowa, Walczak 1997; PpK; edukacyjno-kulturalny projekt Muzeum Miasta Łodzi „Ludzki język łódzki” z 2014 r. (http://jezyk.muzeum-lodz.pl/ [dostęp 6.01.2019]. Idea regionalizmu przekracza granice, za przykład może posłużyć Лексикон львівський: поважно і на жapm (LL).

13 Warszawski złodziej i bandyta, ps. Krwawy Feluś. Za śmiertelne ugodzenie nożem policyjnego agenta i ciężkie zranienie przy próbie aresztowania dwóch pozostałych (niektóre źródła mówią o potrójnym zabójstwie), został zesłany dożywotnio na Sybir, skąa prawdopodobnie zbiegł i kontynuował swój przestępczy proceder w przedwojennej Warszawie. Jest bohaterem więziennej piosenki i podwórzowej ballady Ballada o Felku Zdankiewiczu, która uczyniła go najsławniejszym warszawskim przestępcą. 
że w istocie reprezentują często - jak w interesującym nas wypadku - krakowski półświatek, społeczny margines, który rozlokował się ok. 1,5 km od bram średniowiecznego Krakowa. Kultura krakowskiego przedmieścia doczekała się nie tylko rozmiłowanych $\mathrm{w}$ folklorze kontynuatorów, ale i piewców, popularyzatorów, z których wymienić można Andrzeja Kozioła, Michała Kozioła wspomnianych już Katarzynę Siwiec i Leszka Piskorza, Leszka Mazana, Mieczysława Czumę i wielu innych. Co ciekawe, doceniana ostatnio miejska gwara krakowska zawędrowała do projektów internetowych krakowskiego hip-hopu i rapu Chodź na pole ${ }^{14}$ (2013 r.), na wzór innych wielkich miast staje się obecna w tekstach reklamowych, nazwach firmowych (kupseto.pl), na koszulkach (napis: chodźże na pole); magistrat namawia nią do nieużywania do głośnych rozmów w tramwajach telefonów komórkowych (nie gadajże głośno), a Cracovia i Wisła zapraszają nią na swoje mecze (weźże przyjdź na mecz; nie siedźże w domu, chodźże na mecz). Można się spodziewać szerszej jej obecności w przestrzeni komunikacyjnej miasta. Można się spodziewać wielu dalszych prób opowiedzenia historii, której nie ma.

Trzeba tu postawić pytanie, czy rzeczywiście wzrosła popularność miejskiego folkloru i języka przedmieść Krakowa, czy też zmieniła się jego ocena, sam sposób postrzegania zjawiska. Za dziennikarzem warto powtórzyć nurtującą także mnie wątpliwość, czy w dzisiejszych czasach miejski folklor tkwiący korzeniami w końcu XIX w. może być jeszcze atrakcyjny dla młodych ludzi? Indagowana Katarzyna Siwiec jest optymistką, podkreśla, że przyciąga tym, że jest autentyczny, krakowski i jedyny w swoim rodzaju ${ }^{15}$. Trudno jednak nie dostrzec, że jest to swoista kulturalna archeologia i promocja regionalności. Aleksander „Makino” Kobyliński, ostatni krakowski andrus, którego przedstawia załączone zdjęcie, $\mathrm{z}$ całym należnym mu szacunkiem, pozostaje pewną pamiątką, znakiem lokalności, zanikającej obecności tradycji przedmieścia w kulturze miasta.

14 Por.: https://muzyka.interia.pl/hip-hop/news-krakowski-rap-kontratakuje-chodz-napole,nId,1660029; http://lovekrakow.pl/aktualnosci/niech-inni-zrobia-cos-lepszego-raperzyopowiadaja-o-klipie-chodz-na-pole_4838.html [dostęp 8.01.2019].

15 Ale czy w dzisiejszych czasach miejski folklor o korzeniach tkwiących w końcu XIX w. może być jeszcze atrakcyjny dla młodych ludzi? Katarzyna Siwiec odpowiada, że tak, bo jest autentyczny, krakowski i jedyny w swoim rodzaju. Opowiada też, jak zbierając materiały do swojej książki o Zwierzyńcu, zagłębiała się w tę tematykę. Okazało się, że poza powszechnie w Krakowie znanymi zwierzynieckimi wątkami, takimi jak Lajkonik i Emaus, jest tu jeszcze cała nieodkryta kultura, barwna i fascynująca. - Kto wie, że wśród tutejszych andrusów obowiązywał kodeks honorowy zabraniający np. bicia słabszego, a w stosunku do dam nakazujący szarmanckość i kulturę? - pyta pani Katarzyna. Kto jeszcze pamięta zamknięty w 1991 r. legendarny Bar na Stawach opiewany przez Jerzego Harasymowicza? Albo kto kojarzy postać Cześka Czornego, który rządził wśród zwierzynieckich chłopaków? (http://www.dziennikpolski24.pl/artykul/3907215,placna-stawach-znow-ozyje-jak-za-dawnych-lat-zapraszamy-na-bal,id,t.html) [dostęp 6.01.2019]. 


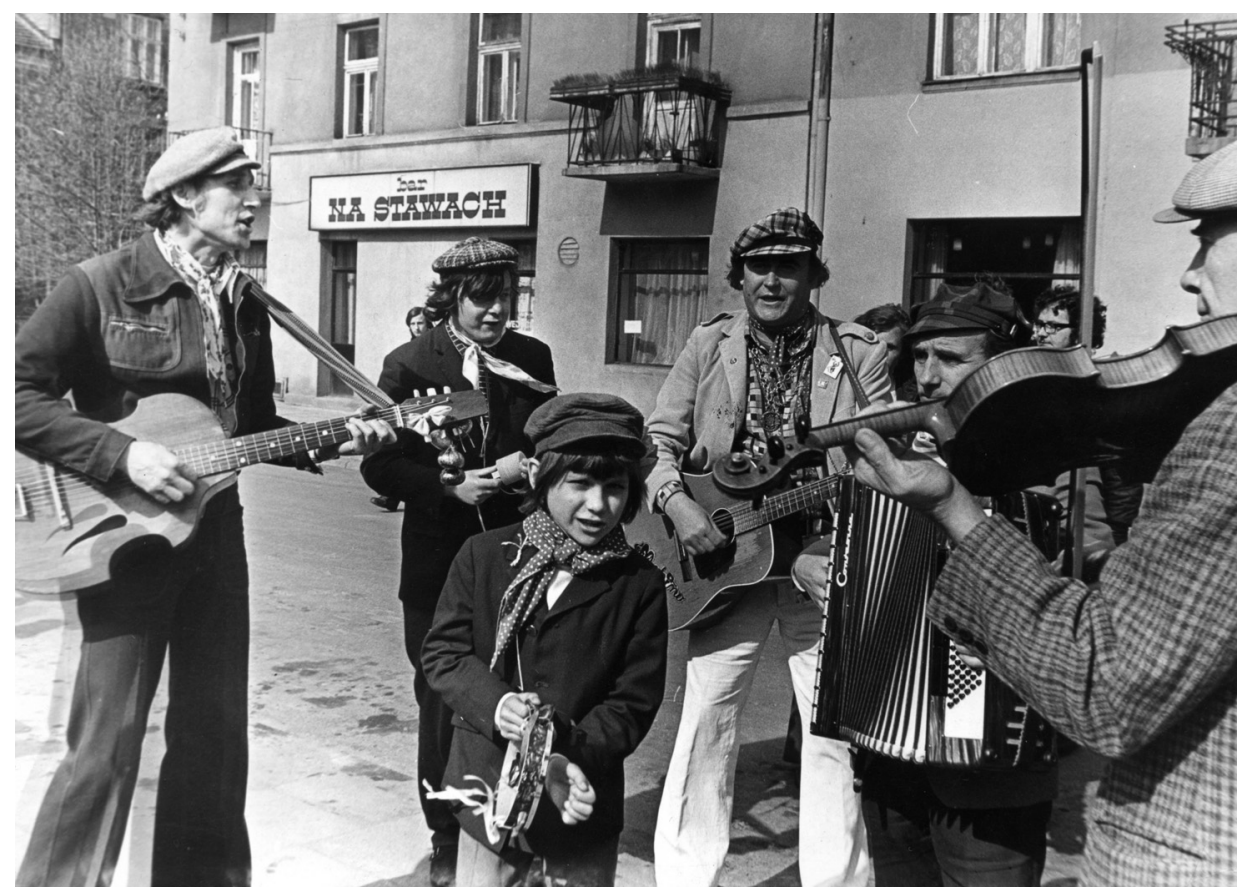

Andrusy, Bar na Stawach na Stawach (ze zbiorów Jarosława Sokoła)

Tak jak np. Stasiek Wielanek ze swą kapelą w Warszawie, śpiewający ballady barda Czerniakowa Stanisława Grzesiuka i piosenki Mariana Hemara; specyficzny strój, sposób noszenia się „pod” bohaterów przedmieścia jest też już kostiumem scenicznym, a nie ubiorem.

Razem z ich właścicielami przenosi się do krakowskiej skrzyni - skarbnicy lokalnej kultury, kryjącej treści, wyobrażenia zmitologizowane, podlegające kulturowej reinterpretacji, metamorfozie. Mamy więc do czynienia z podwójną perspektywą poznawczą: sytuującą postaci folkloru w kontekście realiów historycznych, jak też ich współczesnych wyobrażeń, poza paradygmatem nauki nie podlegającym już weryfikacji.

Z takim, na poły rekonstrukcyjnym zadaniem musieliśmy się zmierzyć, opracowując słownictwo należące do kultury duchowej krakowskiego przedmieścia. Taki sam, $w$ istocie rzeczy, problem stanął przed autorami LL, bowiem włączono do podstawy materiałowej czasy wspólnej polsko-ukraińskiej przeszłości Lwowa i słynnego bałaku (lwowskich batiarów, andrusów i jantków, kindrów/kindrusów ${ }^{16}$ itp.,

16 Lektura opracowania przekonuje, że nazwy ludzi z półświatka regularnie powtarzają się, zachowując tożsame lub podobne znaczenie (nawet zbiorowe paka 'ferajna'), nie wyłączając wielu znanych także w Krakowie ekspresywizmów osobowych i wykrzykników. 
tworzących szemrane towarzystwo tego bardzo bliskiego kulturowo Krakowowi miasta). Daje to dobrą sposobność do porównań.

Pora przedstawić choć kilku spośród tytułowych bohaterów (Agara/Chachara, Andrusa/Andra, Antka, Kindra/Kindrusa). Tworzą oni trzon krakowskiego szemranego towarzystwa, zasadniczo stanowiący już społeczny margines. Z braku miejsca nie może to być opis wszechstronny, ani tym bardziej barwna, zajmująca opowieść. Zdecydowałem się więc jedynie na przedstawienie już usystematyzowanej leksykograficznie (PpK), ujętej syntetycznie wiedzy na ten temat. Jak można się zorientować, próbowano $\mathrm{w}$ opisie ${ }^{17}$ pogodzić wspomniane sprzeczności.

Jak pokazały badania materiałowe i studia nad dostępną literaturą, wśród postaci krakowskiej paki - ferajny najważniejszą i najbardziej rozpoznawalną (także współcześnie) pozostaje andrus/ander. Ten najbardziej charakterystyczny typ ludzki, typowy dla środowisk robotniczych i powstającego tam marginesu społecznego, zamieszkujący przedmieścia przedwojennego i powojennego Krakowa (Zwierzyniec, Grzegórzki, Ludwinów i Krowodrzę) w folklorze miejskim przedstawiany jako miejski spryciarz, "honorowy” cwaniak i lekkoduch, noszący co prawda sprężynowy nóż w kieszeni, ale przestrzegający swoistego kodeksu honorowego (stąd np. u tego łobuziaka - dżentelmena rycerskość wobec kobiet, grzeczność w obejściu, bójka na pięści „solo” jeden na jednego, niekopanie i nieponiżanie powalonego przeciwnika), obdarzony młodzieńczą fantazją, oddający się beztroskiej zabawie, pełen zawadiackiego poczucia humoru ${ }^{18}$. Andrusa, z jego pojęciem elegancji i szyku, wyróżniała pstrokata odzież, kraciaste spodnie rurki (bardziej eleganccy, jak „Makino” Kobyliński nosili spodnie białe lub czarne, prasowane $\mathrm{w}$ kant), takaż (lub w jodełkę) samodziałowa marynarka $\mathrm{z}$ kolorowymi łatami (często noszona na gołe ciało lub na kolorowy podkoszulek na ramiączkach), kraciasta czapka kaszkietowa w intensywnym kolorze (żółtym lub czerwonym), krzykliwy krawat lub apaszka i lśniąca od brylantyny lub kremu (w ostateczności tłuszczu) fryzura, w latach 60. ubiegłego wieku naśladująca uczesanie Elvisa Presleya. Specyficznie pojmowany szacunek nakazywał andrusom bronić honoru kobiet i słabszych mieszkańców własnej dzielnicy przed „obcymi” z innych dzielnic, zwłaszcza tępić frajerów niezasługujących na szacunek „swoich”. Z tym noszącym cechy autostereotypu wyobrażeniem, ukształtowanym

17 Wykorzystano robocze wersje tych haseł, przygotowane dla PpK. Ze względu na brak miejsca pominięto zarówno opis fleksyjny, jak i przykłady użyć.

18 Skrupulatne ustalenie (drogą swobodnych wywiadów) rozmaitych elementów tych wyobrażeń krakowskiego andrusa, nie wyłączając jego stroju i zwyczajów, zawdzięczam pani Dorocie Czarneckiej, która napisała na Wydziale Polonistyki UJ pod kierunkiem prof. dr hab. Renaty Przybylskiej pracę magisterską na temat funkcjonowania andusów, dżolerów, brzan i reszty krakowskiej „paki” w językowo-kulturowym obrazie świata. Dane te podaje się tu za wiedzą i zgodą autorki, zamieszkującej (z niewątpliwą szkodą dla polskiej nauki) od kilku lat w Bawarii. 
niewątpliwie pod wpływem lokalnej tradycji i literatury (idzie tu o niesłychaną wręcz i trwającą niezmiennie od 22 lipca 1898 roku przez dziesiątki lat popularność ${ }^{19}$ świetnie portretującego ludzi i język przedmieścia (por. Godyń 1972) wodewilu Konstantego Krumłowskiego Królowa Przedmieścia, a po nim Krowoderskich Zuchów (1910) i Loli z Ludwinowa (1914) S. Turskiego) kontrastuje jeszcze obecny w języku starszych krakowian, recesywny, negatywny wizerunek andrusa - jako budzącej lęk i odrazę „(pod)miejskiej szumowiny”, łobuza i chuligana, złodziejaszka i kombinatora, spędzającego życie na ulicy.

Stąd wynika bliskość znaczeniowa (nawet synonimia?) z agarem/chacharem, rzeczywistym już przedstawicielem krakowskiego półświatka; także mieszkańca przedmieść, ale utrwalonego w folklorze miejskim jako człowiek młody, zuchwały, skłonny do wszczynania bójek i występków, jawnie lekceważący prawo i normy życia społecznego. Stąd krok tylko do współczesnego utożsamienia agara z miejskim chuliganem i łobuzem „zakapiorem”. Próby ustalenia znaczenia tych nazw utrudniają przekazy popularyzatorów wiedzy o Krakowie: np. chachar (synonim agara, znany dziś głównie w wulgarnych piosenek biesiadnych, np. A chachary żja...) zyskał w rezultacie znaczenie 'miejskiego cwaniaka i dowcipnisia', by na dowód zacytować tu budzące niejaką wesołość (zamiłowanie do oranżady) zdanie Katarzyny Siwiec, wyrażone w książce Andrusów król (2010):

Chachar - cwaniak i dowcipniś, ale żaden społeczny degenerat. W piosence „A chachary żyją i gorzałę piją", na potrzeby rymu posłużono się insynuacją. Klasyczne chachary owszem, piły, ale krachlę, co najwyżej piwo.

Pozostaje nakreślić jeszcze wizerunek kindra/kindrusa, którego na tle krakowskiego szemranego towarzystwa wyróżnia przede wszystkim młody wiek (związek etymologiczny z niem. Kinder ${ }^{20}$ 'lm. dziecko, chłopiec') i miejsce na mapie przedmieść (głównie Zwierzyniec i Grzegórzki). W rezultacie w miejskim folklorze utrwalił się w podstawowym znaczeniu jako 'pełen fantazji, zadziorny młodzieniec, brzydzący się ciężką pracą cwaniak prowadzący beztroskie, rozrywkowe

19 Według wiarygodnych relacji w ciągu 2 miesięcy od premiery Królową Przedmieścia obejrzało 40 tysięcy ówczesnych krakowian (połowa wszystkich mieszkańców miasta). Zachwycał się tym wodewilem Stanisław Przybyszewski. Krakowskie wodewile należały do 1986 roku do stałego repertuaru krakowskiego „plebejskiego” Teatru Kolejarza, gdzie grywali także wybitni aktorzy scen krakowskich. Jeszcze po wojnie wystawiały je liczne teatrzyki amatorskie w podkrakowskich wioskach, dokąd komunistyczne władze PRL, likwidując struktury ZMW „Wici” [Związek Młodzieży Wiejskiej „Wici” (od red. D.R.)] i OM TUR [Organizacja Młodzieży Towarzystwa Uniwersytetu Robotniczego (od red. D.R.)], nie położyły kresu tej integrującej lokalne wspólnoty działalności (np. w moich rodzinnych Bronowicach młodzież przygotowała i wystawiła do 1948 roku aż 16 spektakli). Nie inaczej było w innych ciążących ku miastu wsiach-osiedlach.

20 Dziś po niemiecku jest das Kind, a Kinder to forma liczby mnogiej, ale pochodzenie wyrazu wskazuje, że pierwotnie w liczbie pojedynczej mogło być kundr (przyp. red. DR). 
życie kosztem innych. Co ciekawe, strój i sposób bycia kindra polegał na naśladowaniu starszych - andrusów, których grono z czasem zasilał. Przez związek $\mathrm{z}$,nobilitującym” kulturowo miejscem i pozytywnymi konotacjami młodości ${ }^{21}$ wytworzyło się także znaczenie poboczne: 'dziecko przedmieścia, etniczny, „prawdziwy" krakus, urodzony i wychowany na przedmieściu, zwł. ze Zwierzyńca, Ludwinowa, Grzegórzek'.

Na koniec tego wybiórczego przeglądu warto wspomnieć o prawie zapomnianym już krakowskim antku - sympatycznym dziecku ulicy ${ }^{22}$, odpowiedniku paryskiego gawrosza, psotnym uliczniku z przedmieścia naciągającym turystów na datki, szukającym jakiegoś zarobku i posiłku w okolicach Rynku Głównego. Kraków, podobnie jak Lwów miał także swoich baciarów, których tu zwykle utożsamiano $\mathrm{z}$ hulakami i niebieskimi ptakami, wiodącymi beztroskie, wypełnione pijacką zabawą "rozrywkowe” życie. W takim też znaczeniu słowa baciar, baciarka, baciarować itp. utrwaliły się nie tylko w gwarze miejskiej Krakowa, ale też w gwarze krakowskiej.

Gwoli naukowej rzetelności dodajmy, że w wypadku większości omówionych kulturowych leksemów dostrzec można istotne podobieństwa do nazw używanych wśród mieszkańców przedwojennego Lwowa, w jakiś sposób przechowanych dzięki popularności lwowskiego bałaku i folkloru śpiewanego. Uznając naukową wiarygodność LL, dostrzec można jednak spore odrębności, które wynikają głównie $\mathrm{z}$ nieuwzględniania sfery konotacji systemowych i kulturowych, wpływających na współczesne rozumienie słowa (por. np.: antek/jantek 'chuligan, złodziej, ulicznik'; andrus/jandrus 'chłopiec-ulicznik, chuligan, łobuz' także 'złodziej'; kinder/kindrus 'złodziej przestrzegający zasad złodziejskiego honoru' lub 'człowiek odważny, pewien siebie; zawadiaka, chojrak'; znaczeniowo nadrzędnym wobec nich wydaje się polisemiczny leksem batiar, któremu LL poświęca zdecydowanie więcej uwagi i obyczajowo-etnograficznych komentarzy, co pośrednio dowodzi także jego żywotności we współczesnej leksyce miejskiej Lwowa.

Cytowany wyżej fragment książki K. Siwiec, każący czytelnikowi wierzyć, że chachary pijały z zamiłowaniem oranżadę i wodę mineralną, prowadzi nas krok dalej, do pytania, jakiej istotnej zmianie uległy te nazwy, skoro dzisiaj funkcjonują w dość odległym od pierwotnego znaczeniu (mimo dostępności poważnej wiedzy na ten temat); por. za blogiem młodego miłośnika Krakowa:

21 Przez pozytywne skojarzenia słowo to używane jest także w odniesieniu do osób starszych, co dobrze tłumaczy nieprzynoszący autorowi żadnej ujmy tytuł autobiograficznej książki Leszka Piskorza Ja, Kinder z Grzegórzek (2008).

22 Za PpK: Antki krakowskie słynęły ze specyficznego, łobuzerskiego dowcipu, psot i ostrego języka, co czyniło z nich swego rodzaju turystyczną atrakcję; z czasem dorastające antki stawały się andrusami, których mali psotnicy starali się naśladować w ubiorze i zachowaniu (s. 80-81). 
Andrus - nastolatek z przedmieścia, który jest dowcipny, zadzierzysty, żwawy szybko się orientujący. Określenie raczej pochlebne.

Agar - chłopak z przedmieścia, który czasami łamał andrusowskie kodeksy postępowania.

Kinder - chłopak z przedmieść Krakowa, http://mareklasyk.blogspot.com/ 2013/11/andrusy-kindry-agary.html [dostęp 14.11.2016].

Narzucającą się obserwacją jest brak negatywnych skojarzeń, powiązania z szemranym towarzystwem, światem społecznych nizin, lumpenproletariatu, z krakowskim półświatkiem w ogólności. Tymczasem kroniki policyjne nie kłamią: chuligański kwiat dzielnicy (andrusy, kindry, dżolery), goszczący częściej na komisariacie, melinie niż w kościele, prowadzący podejrzane interesy, żyjący na bakier z prawem, często na koszt społeczeństwa, bywa że odstręczający wyglądem, z konieczności tylko imający się dorywczych zajęć (bagażowi, noszący węgiel duckorze, majlorze, chodzenie z szopką bożonarodzeniową, łapanie ryb w Wiśle), podlega tu swoistej rehabilitacji i nobilitacji. Historia zgotowała im wybielającą kąpiel. Pośrednikiem w tej kulturalnej przemianie jest oczywiście popularna kultura i folklor, który jako jedyny zdolny jest z często odrażających i budzących lęk postaci uczynić swoich ludowych bohaterów, uczestników jakoby tak barwnego życia krakowskich przedmieść (zwłaszcza Zwierzyńca) - ludzi wolnych, wesołych i dowcipnych, kochających uroki życia i zabawę, lekceważących władzę i narzucony im porządek itp., co razem wzięte jest projekcją oczekiwań i pragnień społeczności na poły wykluczonej, doświadczającej poważnego niedostatku w tym względzie (wolność osobista, ekonomiczna, prestiż).

Nietrudno dostrzec liczne podobieństwa i analogie względem kształtowania się zmitologizowanych wyobrażeń zbójników i zbójnictwa w kulturze polskiej i słowackiej. Z rozmaitych opracowań historycznych, jak pisze Feliks Kiryk, wyłania się zgoła negatywny wizerunek zbójnika i zbójnictwa - „gdyż na jego treść składają się nieszczęścia tysięcy ludzi, setek spalonych i złupionych miejscowości, męczarnie schwytanych sprawców rabunków i rozboju, obraz ponury, daleki od utrwalonego przez literaturę piękną" (Kiryk 2007: 36). Takich ludowych bohaterów, dumnych i „ślebodnych” harnasiów orlim lotem „równających góry z dolinami”, stających w obronie słabych i uciśnionych nie ma w materiałach źródłowych. Jedynie piękne legendy mówią o szlachetnych zbójnikach.

Właściwy, jak się wydaje, trop, odsuwający na bok pokusę trywialnych socjologicznych interpretacji, podsuwa Urszula Janicka-Krzywda, stwierdzając, że kiedy zbójnictwo karpackie stało się dominującym tematem pieśni, podań i legend folkloru słownego, na jego kanwie narodził się mit nawiązujący do starych struktur indoeuropejskich mitów bohaterskich, mających swe korzenie w starożytności (Janicka-Krzywda 2007: 121; 1986). Już Zdzisław Piasecki (1973) zauważył, ze bohaterowie zbójnickich opowieści uosabiają cechy szczególnie bliskie ludowi, 
stanowiące przedmiot społecznych pragnień, obejmujące np. szczególne cechy fizyczne, duchowo-psychiczne, prestiż (wyróżniona pozycja społeczna), dodatnie cechy charakteru (np. odwaga, spryt, dowcip, swoiste poczucie sprawiedliwości, wspaniałomyślność) - a nie tylko wynaturzoną (chęć posiadania) ideę społecznej sprawiedliwości. W recenzji książki Piaseckiego Teresa Komorowska napisała:

Powoli, ale z prędkością jednostajnie przyspieszoną, góralscy zbójcy, ludzie wyjęci spod prawa, pozbywali się w świadomości potomnych swych negatywnych cech i urastali do roli herosów. Legenda wyposażyła ich w nadludzkie możliwości, literatura dodała głęboką mądrość, nauka wreszcie wykreowała na obrońców praw wyższego rzędu, świadomych prekursorów nowego porządku (Komorowska 1974: 380).

Ciekawe dopełnienie tego wątku rozważań przynosi artykuł Barbary Zgamy (2007), w którym autorka zestawiła skrupulatnie w ciągu chronologicznym definicje zbójnika i zbójnictwa występujące w polskich źródłach słownikowych XIX i XX wieku. Ten trud przyniósł pouczające wyniki, bowiem okazało się, że w słownikach XIX-wiecznych dominuje obraz negatywny (zbój, opryszek, członek bandy rozbójników), by w dziełach późniejszych nabrać cech ambiwalentnych i przyjąć też wizerunek pozytywny (szlachetnego chłopskiego rycerza, obrońcy uciśnionych górali, pogromcy złych panów, dumnego i miłującego wolność mieszkańca gór - polskiego patrioty) (Zgama 2007: 385-386).

Wskazując na rozmaite świadectwa: a) obecności wyidealizowanych bohaterów dawnego krakowskiego przedmieścia i miejskiego folkloru we współczesnych, zmitologizowanych wyobrażeniach przeszłości Miasta, i (b) tęsknoty za owym czasem szczęśliwym, życiem pełnym prawdziwych emocji, można zaryzykować tezę, że krakowskie andrusy i kindry podążają w ślad za podhalańskim góralem-harnasiem. Czas pokaże, czy postacie te na trwale zagoszczą w regionalnej polszczyźnie Krakowa i właściwym jej językowo-kulturowym obrazie świata. Istnieją po temu pewne szanse, bowiem tradycja i zbiorowa pamięć chętnie pielęgnują integrujące społecznie przekazy o przodkach zadziornych, zawadiackich i dowcipnych, a przy tym honorowych i w żadnym wypadku chamskich (nawet jeśli są wytworem szemranego folkloru). Nil novi sub sole - Dostojny Panie Profesorze!

\section{Bibliografia}

Bellon Wojciech, Bar na Stawach, http://wiersze.pl/wiersz/106/bellon-wojciech/bar-na-stawach.html [dostęp 12.09.2018].

Chrobaczyński Jacek, 2004, Kraków przed i w 1914 roku, „Dzieje Najnowsze”, t. XXXVI, nr 3, s. 63-78.

Godyń Jan, 1972, Uwagi o gwarze krakowskiej w utworach Konstantego Krumłowskiego, „Język Polski”, r. LII, s. 189-200, 286-295. 
Gruchmanowa Monika, Walczak Bogdan (red.) 1997, Słownik gwary miejskiej Poznania, Poznań.

Harasymowicz Jerzy, 1973, Bar na Stawach, Warszawa.

Jakubowski Krzysztof, 2016, Kraków pod ciemną gwiazdą, Warszawa.

Janicka-Krzywda Urszula, 1986, Niespokojne Karpaty czyli rzecz o zbójnictwie, WarszawaKraków.

Janicka-Krzywda Urszula, 2007, Zbójnicy w karpackim folklorze słownym - wątki i motywy, [w:] Mity i rzeczywistość zbójnictwa na pograniczu polsko-słowackim w historii, literaturze i kulturze, red. Maria Madejowa, Anna Mlekodaj, Maciej Rak, Nowy Targ, s. 121-130.

Kiryk Feliks, 2007, Przyczynki do dziejów zbójnictwa-beskidnictwa na pograniczu polsko-słowackim w XV-XVIII wieku, [w:] Mity i rzeczywistość zbójnictwa na pograniczu polsko-słowackim w historii, literaturze i kulturze, red. Maria Madejowa, Anna Mlekodaj, Maciej Rak, Nowy Targ, s. 26-36.

Komorowska Teresa 1974, [rec.] Zdzisław Piasecki, „Byli chłopcy, byli... Zbójnictwo karpackie - prawda historyczna, folklor i literatura polska”, Kraków 1973, Wydawnictwo Literackie, ss. $348+4$ wklejki ilustr., „Pamiętnik Literacki”, t. 65, nr 3, s. 380-384.

Kracik Jan, Rożek Michał, 2012, Hultaje, złoczyńcy, wszetecznice w dawnym Krakowie, wyd. 3, Kraków.

LL - Наталя Хобзей, Ксеня Сімович, Тетяна Ястремська, Ганна Дидик-Меуш, Лексикон львівський: поважно і на жарт, вид 3-е, доповн. і випр., Львів 2015.

Milewski Stanisław, 2009, Szemrane towarzystwo niegdysiejszej Warszawy, Warszawa

Mrowiec Małgorzata, Stachnik Paweł, : http://www.dziennikpolski24.pl/artykul/3907215,plac-na-stawach-znow-ozyje-jak-za-dawnych-lat-zapraszamy-na-bal,id,t.html [dostęp 6.01.2019 r.].

Piasecki Zdzisław, 1973, Byli chłopcy, byli... Zbójnictwo karpackie - prawda historyczna, folklor i literatura polska, Kraków.

Piskorz Leszek, 2008, Ja, Kinder z Grzegórzek, Kraków.

PpK - Powiedziane po krakowsku. Słownik regionalizmów krakowskich, red. Donata Ochmann, Renata Przybylska, Kraków 2017.

Siwiec Katarzyna, 2010, Andrusów król, Kraków.

Siwiec Katarzyna, 2014, Idze, idze bajoku... Rzecz o krakowskim Zwierzyńcu, Kraków. Skowroński Jaroslaw, 2003, Kraków cesarsko-królewski, Łódź.

Wieczorkiewicz Bronisław, 1971, Warszawskie ballady podwórzowe, Warszawa.

Zgama Barbara, 2007, Wizerunek zbójnika i zbójnictwa w XIX- i XX-wiecznych źródłach leksykograficznych, [w:] Mity i rzeczywistość zbójnictwa na pograniczu polsko-słowackim w historii, literaturze i kulturze, red. Maria Madejowa, Anna Mlekodaj, Maciej Rak, Nowy Targ, s. 378-388. 


\section{Streszczenie}

Autor zajął się (na przykładzie języka regionalnego Krakowa i jego przedmieść) obecnością tradycyjnego folkloru miejskiego we współczesnej przestrzeni symbolicznej miasta. Nowy, pozytywny wizerunek dawnych agarów, andrusów i kindrów (i innych ludzi z półświatka) jest - jego zdaniem - głównie wynikiem mitologizacji przeszłości, która cechuje współczesny dyskurs regionalności. 